\title{
EFIKASI DIRI KADER ANTI PENYALAHGUNAAN NARKOBA BERBASIS PELAJAR DI SMA SURABAYA
}

\author{
Self Efficacy of Drug Abused Student-Based Cadre in Surabaya High School \\ 1Rima Diana Nurrilla \\ ${ }^{1}$ Departemen Promosi Kesehatan dan Ilmu Perilaku, \\ Fakultas Kesehatan Masyarakat, Universitas Airlangga, Surabaya. \\ Email : rimadiana25@gmail.com
}

\begin{abstract}
Drug abuse has increased each year and and has spread to adolescents who are still in school. Goverments city of Surabaya issued preventive drug abuse policies (Perwali) Number 65 of 2014about policies and strategies for the area in the field of prevention, combating drug abuse and illict drugs (P4GN). One of the priority programs of the Government of the city of Surabaya is forming student-based cadre. The formation of drug abused student-based cadre is a form of social reinforcement among students. The purpose of the research is to find out academic self efficacy of drug abused student-based cadre in Surabaya High School. This research is descriptive research with using qualitative approach. The results showed that self efficacy of drug abused student-based cadre can be seen through the dimension level, the dimension of generality, and dimensions of strenght. Dimension level faced cadres was considered patronizing by friends, many of friends are less open regarding their problems, and the issue abaout time management.The dimension of generality is obtained because the respondents consider they are able to carry out his duties as motivate friends, discussions, sharing drug-related information to a friend, an extension of the hand counselor teacher and positive activities that lead to prevention drugs. The dimensions of the strenght that is owned by the respondent based on some of the things that is add to the experience and insights, like to help friends, fighting drugs and because chosen to represent the school.
\end{abstract}

Keywords: self efficacy, cadre, drug abused

\begin{abstract}
Abstrak
Penyalahgunaan narkoba semakin meningkat tiap tahunnya dan mulai merambah kalangan remaja yang masih sekolah. Pemerintah Kota Surabaya mengeluarkan kebijakan terkait pencegahan penyalahgunaan narkoba yaitu adanya Peraturan Walikota (Perwali) Surabaya nomor 65 tahun 2014 tentang rencana aksi kebijakan dan strategi daerah bidang pencegahan, pemberantasan penyalahgunaan, dan peredaran gelap narkoba (P4GN). Salah satu program yang menjadi prioritas pemerintah Kota Surabaya yaitu pembentukan kader anti penyalahgunaan narkoba berbasis pelajar. Pembentukan kader anti penyalahgunaan narkoba adalah bentuk penguatan sosial di kalangan pelajar. Penelitian ini bertujuan untuk menggambarkan efikasi diri kader anti penyalahgunaan narkoba berbasis pelajar di

${ }^{1}$ Rima Diana Nurrilla adalah Departemen Promosi Kesehatan dan Ilmu Perilaku Fakultas Kesehatan Masyarakat Universitas Airlangga
\end{abstract}


SMA Surabaya. Penelitian ini adalah penelitian deskriptif dengan menggunakan pendekatan kualitatif. Hasil penelitian menunjukkan bahwa efikasi diri yang dimiliki kader anti penyalahgunaan narkoba berbasis pelajar dapat dilihat melalui dimensi level, dimensi generality, dan dimensi strenght. Dimensi level yang dihadapi kader yaitu dianggap menggurui oleh teman, banyak teman yang tertutup, dan masalah pembagian waktu. Dimensi generality diperoleh karena responden menganggap mereka mampu untuk melaksanakan tugasnya seperti memotivasi teman, diskusi, berbagi informasi terkait narkoba ke teman, perpanjangan tangan guru BK dan kegiatan positif yang mengarah pada pencegahan narkoba. Dimensi strenght yang dimiliki oleh responden didasari oleh beberapa hal yaitu menambah pengalaman dan wawasan, ingin membantu teman, memerangi narkoba serta karena dipilih untuk mewakili sekolah.

Kata Kunci : efikasi diri, kader, penyalahgunaan narkoba

\section{PENDAHULUAN}

Masalah narkoba saat ini menjadi sorotan dan membahayakan. Jumlah penyalahguna narkoba di dunia meningkat dari tahun 2015 hingga 2016 menjadi 20 juta jiwa. Sejumlah 5,6\% dari populasi dunia atau sejkitar 275 orang menggunakan narkoba di tahun 2016. Survei di berbagai negara menunjukkan bahwa jumlah pengguna narkoba lebih banyak pada kalangan remaja dibandingkan pada orang dewasa. Remaja usia 12-17 tahun adalah periode kritis untuk melakukaan penyalahgunaan narkoba (UNODC, 2018).

Permasalahan narkoba di Indonesia juga mengkhawatirkan. Masalah narkoba di Indonesia dipengaruhi oleh perkembangan fenomena yang ada saat ini. Salah satunya adalah perkembangan teknologi yang seiring dengan erkembangan kejahatan narkoba yang semakin canggih dan teroganisir(Ekasiwi, 2016). Angka prevalensi penyalahguna narkoba di Indonesia sebesar $1,77 \%$ dengan jumlah pengguna narkoba di tahun 2017 mencapai 3.376.115 jiwa(BNN, 2017). Tingginya kasus narkoba di Indonesia membuat pemerintah menerbitkan kebijakan melalui Instruksi Presiden
Nomor 12 tahun 2011 tentang Pencegahan, Pemberansatan, Penyalahgunaan dan Peredaran Gelap Narkotika, Psikotropika dan Bahan Adiktif lainnya kecuali bahan adiktif untuk tembakau dan alkohol.

Jawa Timur sebagai kota terbesar kedua di Indoenesia menghadapi permasalahan yang sama terkait narkoba dan peredarannya. Prevalensi penyalahgunaan narkoba di Jawa Timur pada tahun 2017 sebesar 1,72\% dengan jumlah penyalahguna narkoba sebesar 492.157 jiwa. Jawa Timur mengalami permasalahan kerugian biaya sosial ekonnomi akibat penyalahgunaan narkoba, bahkan menjadi provinsi kedua dengan kerugian tertinggi di Indonesia setelah Jawa Barat(BNN, 2017). Tingginya masalah penyalahgunaan narkoba di Jawa Timur melatarbelakangi di keluarkannya kebijakan Pergub Nomor 74 tahun 2012.

Salah satu Kota di Jawa Timur yang berisiko terkait masalah penyalahgunaan narkoba yaitu Kota Surabaya. Kota Surabaya merupakan kota terbesar kedua di Indonesia dengan jumlalah penduduk terbanyak di Provinsi Jawa Timur mencapai 2.847.700 jiwa di tahun 2017(BPS, 2018). Jumlah pengguna narkoba di Kota Surabaya 
tahun 2017 sejumlah 296 jiwa, angka tersebut turun dari 2 tahun sebelumnya yaitu ditahun 2015 sejumlah 424 jiwa dan tahun 2016 sejumlah 364 jiwa (BNNK Surabaya, 2018). Meskipun angka rpenyalahgunan narkoba di Kota Surabaya turun dalam 3 tahun terakhir, akan tetapi persebarannya sudah merambah kalangan remaja baik pada tingkat pendidikan Sekolah Dasar, Sekolah Menengah Pertama, Sekolah Menengah Atas, maupun Perguruan Tinggi.

Pengedar dan pengguna narkoba di Kota Surabaya sudah merambah ke kalangan remaja yang masih sekolah. Remaja rentan dan mudah terjerumus ke dalam hal-hal negtaif yang dapat merugikan diri mereka. Motif perilaku remaja menyalahgunakan narkoba di Kota Surabaya yaitu untuk menenangkan pikiran dan menggunakannya sebagai bahan pelarian serta menunjukkan rasa solidaritas antar teman sekelompoknya (Madyaratri \& Wahyudi, 2017).

Salah satu kebijakan yang dikeluarkan pemerintah Kota Surabaya terkait pencegahan penyalahgunaan narkoba yaitu adanya Peraturan Walikota Subaya nomor 65 tahun 2014 tentang rencana aksi kebijakan dan strategi daerah bidang pencegahan, pemberantasan penyalahgunaan, dan peredaran gelap narkoba. Terdapat beberapa program terkait pencegahan narkoba yang menjadi prioritas pemerintah Kota Surabaya yaitu pembentukan kader anti penyalahgunaan narkobaberbasis pelajar(Pina \& Soedirham, 2015). Pelaksanaan program pencegahan penyalahgunaaan narkoba sesuai dengan Perwali memerlukan dukungan dari pemerintah Kota Surabaya. BNN sebagai salah satu lembaga yang menangani masalah narkoba menetapkan lingkungan pendidikan sebagai saasaran strategis program pencegahan penyalahagunaan narkoba (BNN, 2009). Pembentukan kader anti penyalahgunaan narkoba adalah bentuk penguatan sosial di kalangan pelajar. Kader anti penyalahgunaan narkoba dibentuk dari berbagai kalangan seperti, siswa di sekolah, mahasiswa di perguruan tinggi, pekerja swasta hingga pekerja instansi pemerintah. Seorang kader nati narkoba memiliki pengetahuan, kemampuan, dan pola pikir kritis dalam hal pencegahan penyalahgunaan narkoba. Kader adalah seseorang yang dipilih oleh masyarakat yang mau dan mampu berkontribusi dalam berbagai kegiatan kemasyarakatan secara sukarela. Kader memiliki peran penting dalam pelayanan kesehatan di masyarakat Peran kader anti penyalahgunaan narkoba meliputi peran sebagai Peer Counseling, Peer Educator, dan Peer Leadership(Sari, 2017).

(Rizqi, et al., 2017)dalam sebuah penelitian menemukan bahwa konselor sebaya belum mempunyai efikasi diri yang baik. Mereka merasa belum mampu menjalankan tugas sebagai konselor sebaya dengan baik karena merasa belum mempunyai pengalaman, pengetahuan, dan ketrampilan terkait tugasnya sebagai konselor sebaya. Efikasi diri adalah perasaan dan penilaian seseorang tentang kemampuan dan kompetensi individu dalam menyelesaikan tugas yang diberikan kepadanya. Efikasi diri merupakan evaluasi individu terhadap kemampuan dan kompetensi yang dimiliki untuk melakukan sebuah tugas, mencapai tujuan, atau mengatasi hambatan(Bandura, 1997). Menurut Bandura (1997) efikasi diri seseorang dapat dilihat melalui tiga dimensi yaitu level (kesuliatan tugas), generality (luas bidang), dan strenght (kekuatan). Efikasi 
diri terhadap kemampuan diri untuk mengembangkan karakter dan menjalankan peran dan tugas kader anti penyalahgunaan narkoba merupakan modal bagi keberhasilan program kader anti penyalahgunaan narkoba berbasis pelajar di sekolah dalam upaya pecegahan penyalahhgunaan narkoba. Penelitian ini bertujuan untuk menggambarkan efikasi diri kader anti penyalahgunaan narkoba berbasis pelajar di SMA Kota Surabaya.

\section{METODE}

Penelitian ini adalah penelitian deskriptif dengan pendekatan kualitatif. Penelitian dilakukan dengan mendeskripsikan dan menganalisa secara mendalam efikasi diri pada kader anti penyalahgunaan narkoba berbasis pelajar di SMA Surabaya. Penelitian ini dilaksanakan pada bulan Maret sampai September 2018 di Sekolah Menengah Atas di Kota Surabaya (terbagi pada 5 region) Surabaya Barat, Timur, Selatan, Utara, dan Pusat). Masing-masing region diambil 2 sekolah sehingga total terdapat 10 sekolah yang akan menjadi sasaran penelitian. Pemilihan sekolah berdasarkan criteria bahwa siswa di sekolah tersebut pernah mengikuti pelatihan kader anti penyalahgunaan narkoba berbasis pelajar pada 2 tahun terakhir. Karakteristik subjek dalam penelitian ini yaitu siswa yang menjadi kader anti penyalahgunaan narkoba berbasis pelajar di masing-masing sekolah yang telah ditentukan. Subjek yang digunakan dalam penelitian ini berjumlah 46 orang. Pengambilandata dilakukan secara kualitatif dengan menggunakan metode indepth interviewdanmetode Focus Group Discussion (FGD) jika terdapat lebih dari
6 kader anti penyalahgunaan narkoba di satu sekolah.

Teknik analisis data yaitu hasil indepth interview dan FGD dengan kader anti penyalahgunaan narkoba berbasis pelajar selanjutnya dibuat transkrip. Data yang telah terkumpul kemudian dianalisis dengan membaca kembali keseluruhan teks yang ada kemudian meringkasnya dan menghilangkan duplikasi-duplikasi. Selanjutnya membuat pengkodean (coding) atau klasifikasi data yang memilkii kemiripan atau kecocokan dengan data lain. Hasil dari proses coding atau klasifikasi data kemudian dibuat label (labeling). Setelah dilakukan labeling akan memunculkan pola-pola umum atau tema-tema yang mengikat pikiran yang satu dengan yang lainnya. Tahap berikutnya merupakan analisis data yaitu mengkonstruksikan framework untuk mendapatkan esensi dari data yang telah diperoleh dan dikaji dengan teori yang digunakan (Raco, 2010). Triangulasi sumber dilakukan untuk meningkatkan kredibilitas dalam penelitian ini. Triangulasi dilakukan dengan melakukan wawancara dengan informan tahu. Kriteria informan tahu dalam penelitian ini yaitu mengenal subjek, tahu keseharian subjek dan bersedia menjadi informan tahu.

\section{HASIL DAN PEMBAHASAN}

Kategorisasi data dikelompokkan kedalam tiga komponen dalam dimensi efikasi diri. Ketiga komponen dimensi efikasi diri tersebut meliputi dimensi level, dimensi generality dan dimensi strenght.

\section{Dimensi Level (Kesulitan Tugas)}

Berdasarkan hasil penelitian terkait dimensi level yang dilakukan pada 46 responden di 10 SMA yang berbeda, 
diperoleh jawaban yang hampir sama berikut cuplikan hasil kuotasis penelitian.

"Tabrakan dengan jadwal sekolah, kegiatan yang terlalu padet, teruskan kadang ada anak yang terbuka ada juga yang gak nah cari informasi dari anak itu masalahnya tu apa agak susah " (JA, SMA A)

"Temen susah kumpul, soalnya mereka ikut eksul lain, sama-sama sibuknya" (NL, SMA A)

"Hambatan administrasi itu pasti awalnya ada itu masih secara adminstrasi secara social temen-temen pasti awalnya juga Koniku Lapo? dan sebagainya jadiya ada pandangan-pandangan lain seperti itu, ada batasan-batasan seperti itu, ya kita pelan-pelanlah untuk mengubah paradigma" (AS, SMA B)

"Kadang juga kalau anak itu tertutup banget itu juga susah. Curhat ke kita nggak mau keteman-teman yang lain nggak mau ke BK juga nggak mau ke guru-guru yang lain juga nggak mau itu yang paling menjadi hambatan. Jadi kita harus melakukan pendekatan yang halus banget buat mancing"(FGD1,SMAC)

"Negatifnya tuh kan ninggal sekolah, jadi kayak ninggal pelajaran. Tapi kalau positifnya dapet tambahan pengetahuan" (FGD2, SMA D)

"Ya kalau disekolah itu kadang meninggalkan pelajaran itu baru sekali, tapi kalau susahnya sih confident sama materinya itu kadang kurang dikuasai" (HR, SMA E)

"Kalau buat penyuluhan tadi mbak. Ya utamanya sih kendalanya sih masih sungkan ya mbak sama temen-temen, jadi tiba-tiba langsung ngajak jangan gitu kan ya" (AW, SMA F)

"Kalau saya hambatannya pembaguan waktu” (SW, SMA F)

"Kendalanya wakatu, kayak waktu mereka curhat tapi waktunya nggak tepat . Maksudnya kayak waktu jam pelajaran tapi ada temen sekelas yang curhat, jadi waKtunya curhatnya itu" (AI, SMA G)

"Itu tadi kadang kalau dibilangin susah terus kadang juga nggak berani"(FGD3, SMA H)

"Iya, tapi kadang ada yang mau dengerin. Ya udahlah"(VN, SMA I)

Beberapa kesulitan tugas yang dihadapi oleh kader anti penyalahgunaan narkoba di masing-masing SMA di Kota Surabaya dapat dirangkum kedalam tabel berikut.

Tabel 1. Kesulitan tugas kader anti penyalahgunaan narkoba berbasis pelajar

\begin{tabular}{|c|c|c|}
\hline No & Sekolah & Kesulitan Tugas \\
\hline 1 & SMA A & $\begin{array}{l}\text { Dianggap menggurui oleh teman, banyak } \\
\text { teman yang tertutup, dan masalah pembagian } \\
\text { waktu }\end{array}$ \\
\hline 2 & SMA B & Dianggap menggurui oleh teman \\
\hline 3 & SMA C & Teman tertutup \\
\hline 4 & SMA D & Masalah pembagian waktu \\
\hline 5 & SMA E & Masalah pembagian waktu \\
\hline 6 & SMA F & $\begin{array}{l}\text { Dianggap menggurui oleh teman dan masalah } \\
\text { pembagian waktu }\end{array}$ \\
\hline 7 & SMA G & Masalah pembagian waktu \\
\hline 8 & SMA H & Dianggap menggurui oleh teman \\
\hline 9 & SMA I & Dianggap menggurui oleh teman \\
\hline 10 & SMA J & Tidak ada \\
\hline
\end{tabular}

Sumber : Data Primer, 2018 
Berdasarkan data hasil penelitian dapat diketahui dimensi level atau derajat kesulitan tugas yang harus dihadapi oleh kader anti penyalahgunaan narkoba berbasis pelajar. Data hasil penelitian menunjukkan informasi bahwa kesulitan tugas yang dihadapi oleh kader anti penyalahgunaan narkobaberbasis pelajar diantaranya adalah dianggap menggurui oleh teman, banyak teman yang tertutup, dan masalah pembagian waktu. Hanya kader di satu sekolah yang menganggap tidak ada kesulitan untuk menjalankan tugas sebagai kader anti penyalahgunaan narkoba berbasis pelajar. Kesulitan tugas yang dihadapi kader anti penyalahgunaan narkoba di masingmasing sekolah berbeda tergantung dari kemampuan yang dimiliki oleh setiap kader anti penyalahgunaan narkoba. Ada yang menganggap sulit tugasnya sedangkan orang lain menganggap tugas itu mudah. Kesulitan tugas yang dihadapi individu dipengaruhi oleh besar rintangan yang harus dihadapi untuk menyelesaikan masalah tersebut. Kesulitan yang dihadapi kader diantaranya adalah dianggap menggurui oleh temannya dan banyak teman ynag tertutup sehingga kader harus lebih pandai mengkomunikasikan informasi tentang narkoba kepada teman sebayanya. Kendala lain yang idhadapi yaitu maslaaha pembagian waktu, kader mengungkapkan bahwa jadwal kegiatan terkadang berbenturan dengan jadwal pelajaran sehingga mengganggu kegiatan belajar mereka. Hal tersebut juga diperkuat dengan triangulasi sumber yang dilakukan kepada guru BK selaku pembimbing kader anti penyalahgunaan narkoba bahwa terkadang jadwal kegiatan yang melibatkan kader memang berbenturan dengan jadwal pelajaran sehingga kader harus meninggalkan pelajaran untuk mengikuti kegiatan.

\section{Dimensi Generality}

Dimensi generality yaitu memandang sejauh mana seseorang yakin terhadap kemampuann yang dimiliki untuk menghadapi tugas yang diterima mulai dari melakukan aktivitas yang biasa dilakukan hingga yang tidak pernah dilakukannya. Dimensi generality meliputi perasaan kemampuan seseorang pada konteks tugas yang berbeda seperti tingkah lakum kognitif dan afektifnya. Data hasil penelitian terkait dimensi generality yang didapat dari 46 responden di 10 SMA Kota Surabaya mendapatkan bebrapa jawaban yang hampir sama. Berikut adalah hasil kuotasi penelitian.

"Perannya ya kayak kalau ada teman yang murung itu kita harus peka, ditanyain kenapa kamu murung mungkin ada masalah apa kan takutmya kalau missal ada masalah takutnya terjerumus dalam hal-hal negative gitu, motivasi dia kayak gimana, jadi gitu mbak" (DF, SMA A)

"Ya saya beberapa kali sih menangani kalau ada teman2 ada masalah gitu" (AS, SMA B)

"Kayak kalo saya sih ini mengantar dia untuk mencari solusinya dia sendiri gimana yang terbaik buat dia. Jadi membantu memecahkan masalah"(FGD1, SMA C)

"Ya Kadang-kadang ya kasi tau ketementemenn gitu mbak. Kalo misalnya tementemennya ya rada-rada mencurigakan gitu" (FGD2, SMA D)

"Memberi materi tentang gimana NAPZA itu"(HR, SMA E) 
"Karena kita kan kalau misalnya ada temen yang udah langsung kena NAPZA gitu kan ggak bisa bilang jangan gitu kan ggak bisa, harus mendekati pake pendekatan dulu lebih utamanya sih"(AW, SMA F)

"Ya tujuannya itu anak-anak cuman pingin membantu kalo siswa siswa atau siswi yang ada masalah terus bilang ke kita, terus kita ngasih pencerahan, membantu gitu lah pokoknya" (EY, SMA G)
"Kalau yang biasanya yang kita kerjakan itu cari-cari info anak yang nakal terus bilang sama guru BK" (FGD3, SMA H) "Ya ngingetin atau itu mbak, tentang dampaknya narkoba" (CA,SMA I) "seringlah curhat- curhat" (ZZ, SMA J) Beberapa tindakan yang dilakukan oleh kader anti penyalahgunaan narkoba di masingmasing SMA di Kota Surabaya dapat dirangkum kedalam tabel berikut.

Tabel 2. Tindakan yang dilakukan kader anti penyalahgunaan narkoba berbasis pelajar

\begin{tabular}{lll}
\hline No & Sekolah & Tindakan yang dilakukan \\
\hline $\mathbf{1}$ & SMA A & $\begin{array}{l}\text { Memotivasi teman, diskusi } \\
\text { mengadakankegiatanpositifyang } \\
\text { pada pencegahan narkoba }\end{array}$ \\
\hline $\mathbf{2}$ & SMA B & Memotivasi teman \\
\hline $\mathbf{3}$ & SMA C & Memotivasi teman \\
\hline $\mathbf{4}$ & SMA D & Memotivasi teman \\
\hline $\mathbf{5}$ & SMA E & Berbagi informasi terkait narkoba ke teman \\
\hline $\mathbf{6}$ & SMA F & Memotivasi teman \\
\hline $\mathbf{7}$ & SMA G & Memotivasi teman \\
\hline $\mathbf{8}$ & SMA H & Memotivasi teman dan sebagai perpanjangan \\
\hline $\mathbf{9}$ & SMA I & tangan Guru BK \\
\hline $\mathbf{1 0}$ & SMA J & Berbagi informasi terkait narkoba ke teman \\
\hline
\end{tabular}

Sumber : Data Primer 2018

Berdasarkan hasil penelitian diperoleh informasi penguasaan individu terhadap bidang atau tugas yang dikerjakan. Tugas yang dikerjakan kader anti penyalahgunaan narkoba berbasis pelajar antara lain yaitu memotivasi teman, diskusi, berbagi informasi terkait narkoba ke teman, perpanjangan tangan guru BK dan kegiatan positif yang mengarah pada pencegahan narkoba. Sebagian besar responden menungkapkan bahwa tugas utama yang mereka lakukan yaitu memotivasi teman yang sedang memilki masalah. Kader anti penyalahgunaan narkoba bertugas sebagai tempat diskusi dan berbagi untuk teman sebayanya dan membantu memberikan solusi terhadap permasalahan tersebut sehingga teman sebayanya tidak terjerumus kedalam penyalahgunaan narkoba. Responden juga mengatakan bahwa tugas mereka yaitu untuk membagikan informasi terkait bahaya narkoba serta dampak penyalahgunaanya untuk mencegah teman sebayanya terjerumus dalam penyalahgunaan narkoba. Hal tersebut sejalan dengan penelitian yang dilakukan (Sari, 2017) bahwa peran kader sebagai peer counselor yaitu untuk mendengarkan dan memberi solusi terhadap permasalahan narkoba yang dialami oleh teman sebayanya. Sebagai kader anti penyalahgunaan narkoba juga 
memiliki peran sebagai peer educator yaitu memberikan pengetahuan faktual kepada teman sebaya dan informasi tentang bahaya narkobab sehingga mampu membentengi pelajar dari kasus baru. Hal tersebut diperkuat memlaui triangulasi sumber yang dilakukan kepada guru BK yaitu salah satu tugas utama kader adalah menyampaikan informasi tentnag narkoba kepada teman sebayanya dan juga menyampaikan informasi jika ada masalah yang terjadi pada teman sebayanya kepada guru BK.

\section{Dimensi Strenght (Kekuatan)}

Hasil penelitian yang didapatkan

dari 46 responden kader anti "Ya memang dulu passion nya disitu, lebih seneng mengatasi itu sih. Jadikan ada kesadaran temen-temen ini banyak yang diluar pelajaraan. itu merokok, jadi kita sadar itu pintu masuk menuju narkoba dan seterusnya gitu" (AS,SMA B)

"Kalau saya sih tergeraknya karena apa karena lihat teman-temansa ya itu kok anaknya kalao sama guru itu kok kurang komunikasi . Jadi dia biasanya komunikasinya kalosama temen-temen yang lain. Karena itu sayamau" (FGD1, SMA C)

"Jadi mengetahui bahanyanya itu, pingin jadi ikut memerangi. Pinginl angsung menangkap bandarnya" (FGD2, SMA D)

"Ceritanya tu pertama nyasih, ya saya kan ikut pramuka. Nggak tau gimanaya wes secara dipilih aja sama kaka kelas" (HR, SMA E)

"Jadi sebenarnya dari awal itu itungannya dadakan sih ya awal itu. Tiba-tiba ditunjuk sama guru pembimbingnya PMR, saya sama $X$ itu tadi ditunjuk itu buat ikut penyalahgunaan narkoba berbasis pelajar di 10 SMA Kota Surabaya terkait dimensi strenght, didapatkan beberapa jawaban yang hampir sama. Berikut adalah cuplikan kuotasi hasil penelitian "Karena kan dengan jadi peer-educator itu bias mendapatkan pengalaman, terus kadang itu miris lihat banyak remajaremaja jaman sekarang itu kalau pacaran melebihi batas, kalo galau dikit bias ajakan lari ke yang namanya narkoba, kayak broken home juga bias lari ke narkoba, E... jadi lebih kependekatan ,jadi kayak ngasih tau klo dengan narkoba kamu malah lebih hancur, kalo kamu lagi sedih, lagi galau ya jangan lari ke narkoba" (JA, SMAA)

kayak seleksinya gitu. Terus abis itu, itu waktu jumatnya dikasih tahu sabtunya udah seleksi gitu"(AW, SMA F)

"Waktu itu direktrut teman. Soalnya aku itu bantu anak-anak curhat masalah apa aja."(EY, SMA G)

"Inginmepelajarilebihbanyaktentangbaha yanarkoba, apayangasih info tentangpenyalahgunannnarkobatentang yang kenakenagitu"(FGD3, SMA H)

"Ya pengen bantu temen-temen" (CA, SMA I)

"Soalnya kan kan, kalau kita itu kan selain nambah ilmu itu kan juga sering sih kalau mau temen itu sukanya curhat ke saya, emang suka mau cerita-cerita mau mintak saranke saya, terus menurut saya tu menambah ilmu dan bisa nambah wawasan kita kedepannya" (FA SMA J)

Beberapa kekuatan yang dimiliki kader anti penyalahgunaan narkoba di masing-masing SMA di Kota Surabaya dapat dirangkum kedalam tabel berikut. 
Tabel 3 Kekuatan individu menjadi kader anti penyalahgunaan narkoba berbasis pelajar

\begin{tabular}{|c|c|c|}
\hline No & Sekolah & Kekuatan individu mejadi kader \\
\hline 1 & SMA A & Menambah pengalaman dan wawasan \\
\hline 2 & SMA B & Ingin membantu teman \\
\hline 3 & SMA C & Ingin membantu teman \\
\hline 4 & SMA D & Ingin memerangi narkoba \\
\hline 5 & SMA E & Dipilih untuk mewakili sekolah \\
\hline 6 & SMA F & Dipilih untuk mewakili sekolah \\
\hline 7 & SMA G & Dipilih untuk mewakili sekolah \\
\hline 8 & SMA H & Menambah wawasam \\
\hline 9 & SMA I & Ingin membantu teman \\
\hline 10 & SMA J & Menambah wawasan \\
\hline
\end{tabular}

Sumber : Data Primer 2018

Hasil penelitian menunjukkan bahwa responden merasa yakin terhadap kemampuan yang dimiliknya untuk bisa mengatasi masalah narkoba di masingmasing sekolahnya. Keyakinan responden terkait kemampuan untuk mengatasi masalah didasari oleh beberapa alasan. Masing-masing responden memilki alasan yang mendaasari keyakinannya terhadap kemampuan yang dimilki. Alasan yang mendasari responden dalam menjadi kader anti penyalahgunaan narkoba berbasis pelajar diantaranya menambah pengalaman dan wawasan terkait narkoba. Kader juga ingin membantu teman sebayanya ketika ada masalah sehiingga dapat membantu memcahkan masalah mereka tanpa lari ke narkoba. Beberapa kader juga beralasan ingin memerangi narkoba setelah tahu dampak buruk yang diakibatkan oleh penyalahgunaan narkoba. Selain didasari oleh keinginan sendiri ada jug akader yang beralsan karena ditunjuk sehingga merasa meiliki tanggung jawab untuk mewakili sekolah. Hal tersebut diperkuat dengan triangulasi sumber yang dilakukan kepada Guru BK bahwa memang terdapat bebrapa siswa yang ditunjuk untuk menjadi kader karena dirasa mampu berperan menjadi kader dan memiliki kemampuan komunikasi dan sosialisasi yang bagus baik kepada teman sebayanya maupun kepada guru.

\section{SIMPULAN DAN SARAN Simpulan}

Efikasi diri yang dimiliki oleh kader anti penyalahgunaan narkoba berbasis pelajar di SMA Kota Surabaya dapat dilihat melalui dimensi efikasi diri yaitu dimensi level, dimensi generality dan dimensi strenght. Dimensi level atau kesulitan yang dihadapi oleh kader anti penyalahgunaan narkoba berbasis pelajar yaitu dianggap menggurui oleh teman, banyak teman yang tertutup, dan masalah pembagian waktu. Dimensi generality atau keyakinan yang dimilki kader anti penyalahgunaan narkoba berbasis pelajar dalam penguasaan tugas. Keyakinan tersebut diperoleh karena responden menganggap mereka mampu untuk melaksanakan tugasnya seperti memotivasi teman, diskusi, berbagi informasi terkait narkoba ke teman, perpanjangan tangan guru BK dan kegiatan positif yang mengarah pada pencegahan narkoba. Dimensi strenght 
adalah kuatnya keyakinan terhadap kemampuan yang dimilki oleh kader anti penyalahgunaan narkoba berbasis pelajar. Kuatnya keyakinan yang dimilki oleh responden didasari oleh beberapa hal yaitu menambah pengalaman dan wawasan, ingin membantu teman, memerangi narkoba serta karena dipilih untuk mewakili sekolah

\section{Saran}

Disarankan dilakuakan pertemuan secara berkala yang membahasa isu-isu terbaru tentang narkoba, agar informasi yang disampaikan oleh kader anti penyalahgunaan narkoba terpecaya. Perlu dilakukan pelatihan secara berkala untuk kader dan monitoring serta evaluasi kinerja kader agar program kader anti penyalahgunaan narkoba berbasis pelajar tetap berjalan sesuai dengan fungsinya. Perlu adanya kerjasama antara pihak sekolah dan BNN dalam program pencegahan narkoba yang melibatkan kader anti penyalahgunaan narkoba berbasis pelajar.

\section{DAFTAR RUJUKAN}

[1] Bandura, A., 1997. Self Efficacy in Changing Societies. New York: Cambridge Unversity Press.

[2] BNN, 2009. Advokasi Pencegahan Penyalahgunaan Narkoba, Jakarta: Badan Narkotika Nasional.
[3] BNN, 2017. Survei Nasional Penyalahgunaan Narkoba di 34 Provinsi Tahun 2017, Jakarta : Pusat Penelitian dan Informasi.

[4] BNNK Surabaya, 2018. Jakarta: Badan Narkotika Nasional Kota Surabaya.

[5] BPS, 2018. Kota Surabaya dalam Angka, Surabaya: Badan Pusat Statistik Kota Surabaya.

[6] Ekasiwi, A. W., 2016. Kasus Penyalahgunaan Narkoba Di Kalangan Remaja Kota Surabaya tahun 1980-1990. AVATARA eJournal Pendidikan Sejarah, pp. 483-497.

[7] Madyaratri, S. A. \& Wahyudi, A., 2017. Motif Perilaku Menyimpang Remaja dengan Kasus Penyalahgunaan Narkoba di Kota Surabaya. Paradigma, pp. 1-8.

[8] Pina, N. \& Soedirham, 0., 2015. Dukungan Pemerintah Dalam Mencegah Penyalahgunaan Narkoba di Kota Surabaya. Jurnal Promkes, pp. 171-181.

[9] Rizqi, M. A., Nashori, H. F. \& Astuti, Y. D., 2017. Pelatihan Konseling Kesehatan Remaja untuk Meningkatkan Efikasi Diri Konselor Sebaya pada Siswa Sekolah Mengah Atas. Jurnal Intervensi Psikologi, 9(1), pp. 64-77.

[10] Sari, D. M., 2017. Peran Kader Anti Penyalahgunaan Narkoba Berbasis Pelajar oleh Badan Narkotika Nasional Surabaya. Jurnal Promkes, pp. 128-140.

[11] UNODC, 2018. World Drug Report 2018, Vienna: United Nations. 